\title{
Resignations raise questions about OMA finances
}

\author{
n Cite as: CMAJ 2017 August 21;189:E1077-8. doi: 10.1503/cmaj.1095470
}

Posted on cmajnews.com on Aug. 2, 2017.

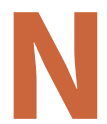

ine doctors are calling for an independent investigation into what they describe as a culture of fear and a lack of financial transparency at the Ontario Medical Association (OMA).

On July 4, Drs. Kulvinder Gill and Mark D'Souza resigned as chairs of the OMA's two largest districts, citing an "increasingly toxic environment." They accused OMA leaders and others in the organization of attempting to muzzle dissent by censoring communications and reporting more than 40 vocal members to the College of Physicians and Surgeons of Ontario (CPSO) for potential discipline.

There was also an "immense amount of bullying and intimidation," including direct threats and insults from people within positions of authority, said Gill. "All attempts to address it internally were met with more bullying and intimidation."

Last week, seven more district delegates resigned in response to OMA's "unwillingness" to address the complaints. They traced the toxicity at OMA to a struggle over financial accountability.

The OMA takes in $\$ 70$ million in revenue each year, with more than $\$ 50$ million coming from mandatory membership dues. However, "there is such a profound lack of transparency about where those funds go," said Gill.

She and the other doctors who resigned questioned why OMA employs nearly 300 administrative staff, and pays potentially hundreds of thousands of dollars in honorariums to physicians appointed by the board to nearly 100 committees.

"Many of the same physicians serve on multiple redundant committees and a physician can make a very handsome salary," Gill explained. "No one knows how much."

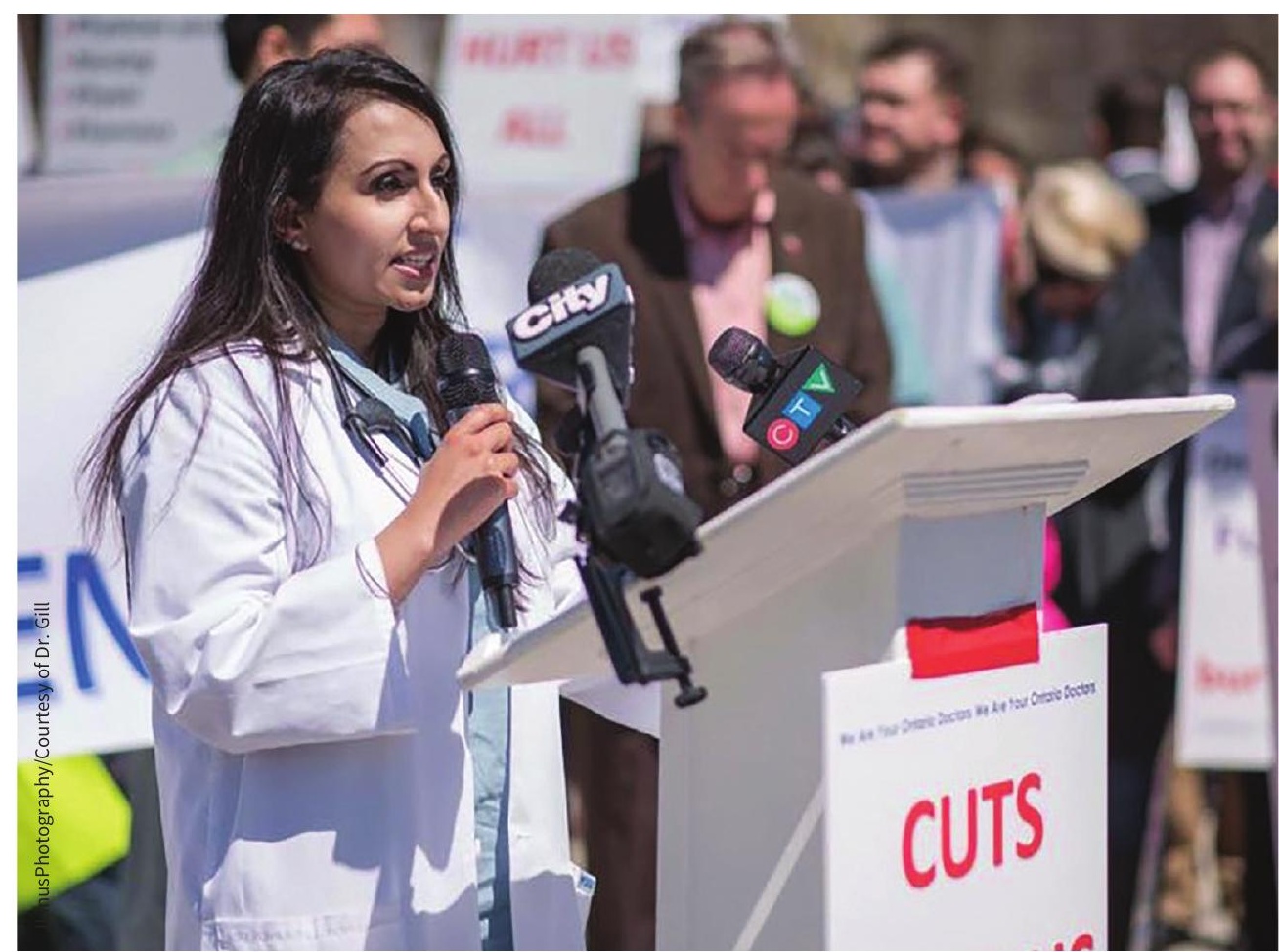

Dr. Kulvinder Gill and eight other physicians say they faced bullying and intimidation after pushing for greater financial transparency.

"Attempts to gain clarity on that have been blocked," she said, including a motion to publish the amounts paid to OMA executive, board, council and committee members. OMA called the motion out of order and blocked its submission to the November 2016 council meeting, Gill said. "We were told that it contravenes privacy."

Other motions were never read at the OMA council in May because time was taken up with long committee reports essentially a filibuster, said Gill.

One of the motions called on OMA to survey members before implementing a code of conduct policy that would empower the organization to report mem- bers to CPSO. The same motion passed in 2016, but OMA still hasn't conducted the survey, Gill said. "When passed motions are ignored and motions supported by membership are blocked or prevented from being read, that's a faux democracy."

Because OMA dues are mandatory, "there's no means of accountability," she added. In other provinces, fees are voluntary or doctors can choose from more than one organization to represent them.

Gill and the others who resigned want an independent investigation to get to the bottom of the bullying and transparency concerns. In March, a former president of the association made a similar 
call for a third-party review, after the entire OMA executive resigned amid reports of escalating abuse within the organization.

"The fact this still hasn't happened, despite so many physicians resigning, makes me believe that the OMA is beyond the point of being able to police itself," said Gill.

\section{OMA response}

Current OMA President Dr. Shawn Whatley called the new wave of resignations "very sad." However, he said that doctors "don't want to keep looking at all the difficulty that we've come through."

Whatley said the OMA is focusing on an overhaul of its mission, vision and values, and a governance review to reduce the number of its board committees from "over 50" to four. "A normal renovation in your house takes six to nine months and we're trying to renovate something that's much more complex."

"Culture doesn't change overnight, either," he added.
Asked what OMA will do to specifically address the complaints about bullying, he said "if people have something specific that they want addressed, please send it in."

He denied that OMA reported anyone to CPSO, but noted that individuals within the organization may have filed complaints. "If a colleague sees something concerning in another colleague, they're going to do what they think is right."

OMA is still finalizing a code of conduct for the organization's November council meeting.

As for concerns about financial transparency, he said "all of this is open to debate" at the OMA council. "That was their opportunity to speak into how things happen." He denied any attempt to block or ignore motions, stating "we usually get through dozens and dozens and dozens."

Asked if Gill or the other doctors raised their concerns internally, Whatley didn't answer directly, but said he "learned about their resignation in the media."
"They had every opportunity to be involved and have their issues heard," he added. Three times during the interview, he said the doctors were talking about events that happened before he became president.

Gill countered that she and others experienced intimidation and bullying "up until the day we resigned," with one doctor receiving a CPSO complaint "two weeks before we resigned," during Whatley's presidency. She also said Whatley was "fully aware" of their concerns and many were brought to him directly. "The most frustrating part of all of this is the denials, denials, denials."

This is why an independent review is critical, she said. "These are serious concerns and it's not going to be swept under the rug, and if OMA is not willing to do it, then Ontario patients and doctors need to be contacting their members of provincial parliament and this needs to become a provincial issue."

Lauren Vogel, CMAJ 